\section{Sibship and self-esteem in children with asthma}

\author{
Concetta Polizzi, 1 Valentina Fontana, 1 \\ Antonio Carollo, 2 Alessandra Bono,2 \\ Sofia Burgio, ${ }^{1}$ Giovanna Perricone ${ }^{1}$ \\ 1Department of Psychological, \\ Educational and Training Sciences, \\ University of Palermo; 2Villa Sofia- \\ Cervello Hospital, University of Palermo, \\ Palermo, Italy
}

\section{Abstract}

This study has explored the valence of sibship that may empower the self-esteem of children with asthma at the interpersonal, environmental control competence, emotionality management, and body-image levels. It has been assumed that the relationship between siblings may have a moderating effect on the negative impact that asthma has on child's development. Seventy children suffering from chronic asthma have been involved: 40 children with siblings (experimental group) and 30 sibling-free children (control group). The children with asthma have exhibited higher levels of self-esteem in comparison with the sibling-free children. The results of the study, at the clinical significance level, highlight how meaningful could be the involvement of healthy siblings to support the development, and to ease the compliance of children suffering from asthma. The outcomes have confirmed the supportive valence of sibship for the self-esteem of the children with asthma.

\section{Introduction}

Asthma is one of the most widespread chronic pathologies in the world, whose first episodes predominantly occur in infancy. Despite asthma is less diagnosed in Italy than in many other countries, either for adults or infants, ${ }^{1}$ (its incidence in infants is about 8$10 \%$ ) it is the main leading cause of hospitalization and school absenteeism among children. ${ }^{2}$ This kind of pediatric conditions are characterized by a developmental and social complexity, ${ }^{3-9}$ due to the diversification of the individual case histories that report various symptoms, different incidence of more or less severe attacks, as well as to a different natural history of the disease in the same child during the developmental trend. ${ }^{10,11}$ Such intricacy is ascribable to the different dysfunctional evolutional outcomes which asthma may bring, and which in turn could lead, according to the
Pediatric Psychology perspective, to the alteration of the dynamic of children's development concerning the relationship between the epistemic bipolarities that are the basis for the dynamic trend: continuity/discontinuity; automatisms/intentionality; nature/culture; etc. 12,13

A cluster of dysfunctionalities are linked to the chronicity of asthmatic pathologies, such as obsessive routines displayed by behavioral stereotypies; 14,15 difficulties related to the distinctive stages of identity construction, 16,17 the lack of focus and attention, ${ }^{8}$ a decreasing sense of self-efficacy, the rigidity of the locus of control, 18 an emotional dysregulation, ${ }^{19}$ marked by the tendency to inhibit negative feelings such as anger and sadness, $, 8,20$ and a dysfunctional use of emotion regulatory strategies in response to the environmental demands. ${ }^{15}$ Emotions that lead to episodes of crying, anger, laugh, or fear can be likely triggers for an asthma attack, since they may cause hyperventilation, hypocapnia, and consequently bronchoconstriction.7,21 It has to be included also, a difficult management of affectivities, ${ }^{22}$ and a significant correlation between anxiety and asthma. 8,23 The fear of asphyxia, which is part of the child's and family's representation of the asthma attack, seems to cause anxiety. ${ }^{14}$ The relationship with peers may be compromised: children with untreated asthma are not able to deliver proper performances during sport activities, so they tend to the social isolation, 8 that heavily affects their quality of life. ${ }^{24}$ Possible severe consequences for the self-image can occur, and frequently lead to a self-devaluation revealed by low levels of self-esteem.

The considerations about these various possible evolutional dysfunctional outcomes brought by asthma pathologies have suggested, according to various studies of the field, 22,25 the need for investigating possible internal, ${ }^{26}$ and external resources of children with asthma as protective factors that may mediate and moderate the impact of the disease on their evolutional wellbeing. Some research studies have dealt with such subject,27,28 and highlighted that specific features of the family functioning, such as the self-confidence, brought by the bond between the child and his parents, a healthy parental psychological functioning, the lack of couple conflicts, the parental skill to foster and develop the emotional self-regulation in children can be significant resource factors for a proper management of the disease, and for the adjustment process of children with asthma.

This study has focused on a variable of the field hardly ever studied such as the relationship with a sibling as a crucial interaction to empower the self-esteem of the child with asthma, unlikely other studies that have only dealt with the implications of having a sibling
Correspondence: Concetta Polizzi, Department of Psychological, Educational and Training Sciences, University of Palermo, Viale delle Scienze - Ed. 15, Palermo, 90128, Italy.

Tel.: +39.091.23897740 - Fax: +39.091 .6513825$

E-mail: concetta.polizzi@unipa.it

Key words: Self-esteem; Sibship; Asthma; Children; Development.

Acknowledgments: the authors would thank all children and adolescents who took part in the research project. Also we thank the medical and psychological team.

Contributions: the authors contributed equally.

Conflict of interest: the authors declare no potential conflict of interest.

Received for publication: 17 December 2015. Accepted for publication: 7 April 2016.

This work is licensed under a Creative Commons Attribution NonCommercial 4.0 License (CC BYNC 4.0).

(C) Copyright C. Polizzi et al., 2016

Licensee PAGEPress, Italy

Pediatric Reports 2016; 8:6370

doi:10.4081/pr.2016.6370

with asthma. ${ }^{25}$ It has been investigated the protective valence that the relationship with a sibling may have for an asthmatic child. It has been hypothesized that not only it could be a friendly and recreational bond, but also a privileged relational context through which the child with asthma can find strength, support and satisfactions. The interaction with healthy siblings may be an empowering resource for the asthmatic child's psychic energy, that could be useful to actively face the difficulties posed by the disease, to foster the quest for wellbeing, as well as to share and release those emotions that the disease could have shelved. ${ }^{29}$ According to the specific model assumed by this study that interprets the sibling relationship as a resource for the asthmatic child's development, ${ }^{30}$ the basis factors of such relationship are: i) the scaffolding factor, a child with asthma may have the possibility to be guided and supported in interpreting and understanding the predictable events linked to the disease and its treatment; ii) the emotional sharing factor, the sick child may have a privileged spot where he/she can release and control anxiety, fears, and negative feelings arisen from the events correlated to the disease and its treatment; iii) the decision making factor, the asthmatic child can find significant stimuli to come to a decision, to deal with specific activities, as well as to undertake to 
accomplish tasks that could get useful to face the critical events.

It has been hypothesized that if a child with asthma perceives a relationship with his sibling based on the above-mentioned factors, his self-esteem will be supported and empowered. However, this vital internal resource, useful to actively and adjustably face the difficulties brought by the disease and treatment, can frequently emerged impaired with possible severe impact on the coping factor. This study has considered self-esteem as the body image as well as the perception of being able to manage interpersonal interactions, to control events and situations, and to handle own emotional world.

\section{Materials and Methods}

Starting from these hypotheses, the objectives are: i) investigate the presence of a significant connection between the self-esteem dimensions (interpersonal relationships, environmental control competence, emotionality, and bodily experience) and the factors related to the perception of sibship as a resource (scaffolding, emotional sharing and decision making factors) in children with asthma; ii) investigate the presence of differences among the self-esteem levels between children with asthma who have siblings, and sibling-free children suffering from the same disease.

\section{Participants}

Seventy children (mean age $=10.4 ; \mathrm{SD}=2.2$ ) suffering from chronic asthma, diagnosed at least one year before the beginning of the survey, have been involved. They have been divided into two groups (experimental and control) on the basis of the existence or lack of the sibship variable. The experimental group was made up of 40 children with asthma (12 females and 28 males) who had at least one sibling; while the control group was made up of 30 sibling-free children with asthma (13 females and 17 males) coupled with the other group for age and chronicity of the pathology.

The children have been collected at the outpatient department of allergology of the Hospital Unit of Pediatrics of the Ospedali Riuniti Villa Sofia-Cervello of Palermo, Italy.

The study has been designed as an interrelated research aimed at having an immediate effect on the work of the physicians of the outpatient department, as well as on the children involved; a sort of a cure-integrated assessment service offered to the patients of the outpatient department (medical check-up, allergies tests, follow-up, etc.). The following procedure has been performed: i) the physician of the outpatient department, together with the psychologist researcher, received parents and children explaining that the department was proposing them an evolutional assessment path to be activated soon after the medical check-up, or while awaiting the results of the allergy tests, in order to monitor the whole developmental path of all children with asthma involved in the research. Then, the psychologist illustrated them the features of the research, and asked parents to sign the informed consent to allow the involvement of their children, and the treatment of the data. ii) The tools of the research were administered soon after, or while awaiting the allergy tests. iii) The physician and the psychologist researcher scheduled the next appointment with the parents and children to perform the clinical monitoring, and to give them back the outcomes of the research tests.

\section{Measures and procedures}

The Test Multidimensionale dell'Autostima (TMA) scale: (the Italian version of MSCSMultidimensional Self-Concept Scale), ${ }^{31}$ is a validated and standardized questionnaire for the evaluation of distinct components of selfesteem. It consists of six 25-item scales: the interpersonal, school success, emotional and family life, corporealness, and environmental mastery scales. However, this research have used only the scales considered most appropriate to the work of the physicians, i.e. the scales of interpersonal relationship, competence, emotionality, and corporealness. The child is invited to express his agreement to a number of statements, and to indicate how true he considers each statement for himself. The answers correspond to a 4-mark Likert scale (totally true; true; untrue; definitely untrue). Adding up the scores of the test gets a gross total of each scale. Each gross total is added up to obtain a global gross total of the child's selfesteem. Hence, through the comparison of the normative scores of TMA, the standard scores are calculated for each scale, and for the total scale referring to self-esteem. The standard scores of each child, related to both individual and global scales, are interpreted according to the range of the standard scores of the standardization sample in order to detect the level of self-esteem of the sample of the research (over 135=extremely positive self-esteem; 126 to $135=$ very positive self-esteem; 116 to $125=$ slightly positive self-esteem; 86 to $115=$ standard self-esteem; 76 to $85=$ slightly negative self-esteem; 66 to $75=$ very negative self-esteem; under $66=$ extremely negative self-esteem). The TMA has excellent psychometric characteristics: a high level of liability (Cronbach's of each scale is $>0.80$ ), and a low standard error of measurement $\left(\mathrm{SE}_{\mathrm{m}}<3.70\right)$. With regard to the correction of the protocols and the counting of the partial and total scores, due to the elimination of the two scales and some items, some calculation expedients planned by the standardized procedures of the tool were applied. ${ }^{31}$

The Brother as a Resource Questionnaire (BRQ): is a tool designed and validated by the Research Unit of Pediatric Psychology of the Psychological, Pedagogical and Educational Sciences Department of the University of the Studies of Palermo. It is aimed at investigating the individual child perception of the sibship as a resource useful to the management of risk events. It is a self-report 21 -item questionnaire that implies 3-point responses of the Likert scale ( $1=$ never; 2 =sometimes; $3=$ =always). The scores of each child concerning the individual factor are interpreted according to specific preestablished range of scores, in order to detect the level of the perception of sibship. The major factors investigated have been: i) the Scaffolding factor (sustaining the accomplishment of a task): it measures how the sibling promotes the development of specific competences, and how he/she helps the other sibling with asthma when he/she has to face the critical events related to the disease and the treatment. Twelve items are used to measure this factor, and the scores vary from 12 to 36 marks. The range of the values useful to interpret the outcomes is: from 12 to $19=$ negative perception; from 20 to $27=$ standard perception; from 28 to $36=$ positive perception. ii) The Emotional sharing factor: it determines the way a sibling may be perceived as a support when sorrowful and difficult moments are experienced. Five items are used to measure this factor through a 3-point Likert scale, and the scores vary from 5 to 15 marks. The range of the values useful to interpret the outcomes is: from 5 to $7=n e g a$ tive perception; from 8 to 11=standard perception; from 12 to $15=$ positive perception. iii) The Decision making during recreational activities factor: it assesses how useful resource a sibling may be when the child has to take a decision related mainly to recreational activities engaging siblings. Four items are used to measure this factor through a 3 -point Likert scale, and the scores vary from 4 to 12 marks. The range of the values useful to interpret the outcomes is: from 4 to $6=$ negative perception; from 7 to $9=$ standard perception; from 10 to $12=$ positive perception . iv) The psychometric characteristics of the tool, such as reliability and validity, were assessed by different methods. The value of Cronbach's alpha, the coefficient of internal consistency, was 0.873 . The applicability of the factorial analysis was assessed via both Kaiser-Meyer-0lkin test (KMO) that provided an index value of 0.877 , and Bartlett's test of Sphericity whose index was null.

\section{Analysis of data}

The data collected have been codified according to the procedures relevant to the tools used, and analyzed via descriptive and 
Table 1. The TMA (test multidimensionale dell'autostima) scores of the experimental group $(\mathrm{N}=40)$ and the control group $(\mathrm{N}=30)$.

\begin{tabular}{|c|c|c|c|c|c|c|c|c|c|c|}
\hline & \multicolumn{2}{|c|}{ Interpersonal scale } & \multicolumn{2}{|c|}{$\begin{array}{l}\text { Environmental } \\
\text { mastery scale }\end{array}$} & \multicolumn{2}{|c|}{ Emotional scale } & \multicolumn{2}{|c|}{$\begin{array}{l}\text { Corporealness } \\
\text { scale }\end{array}$} & \multicolumn{2}{|c|}{ Total scale } \\
\hline & Exp gr & Co gr & Exp gr & Cogr & Exp gr & Co gr & Exp gr & Co gr & Exp gr & Cog gr \\
\hline Raw score & 71.25 & 71.46 & 71.82 & 72.53 & 72.62 & 62.8 & 68.52 & 58.26 & 382.4 & 359.8 \\
\hline Standard score & 94 & 94 & 96 & 96 & 98 & 86 & 94 & 80 & 80 & 75 \\
\hline Confidence interval 90\% & $86-102$ & $86-102$ & $87-105$ & $87-105$ & $91-105$ & $79-94$ & $87-101$ & $73-87$ & $76-84$ & $71-79$ \\
\hline Classification & mean & mean & mean & mean & mean & mean & mean & $\begin{array}{c}\text { lightly } \\
\text { negative }\end{array}$ & $\begin{array}{l}\text { lightly } \\
\text { negative }\end{array}$ & $\begin{array}{c}\text { very } \\
\text { negative }\end{array}$ \\
\hline Percentil rank & $35^{\circ}$ & $35^{\circ}$ & $40^{\circ}$ & $40^{\circ}$ & $44^{\circ}$ & $17^{\circ}$ & $35^{\circ}$ & $g^{\circ}$ & $g^{\circ}$ & $5^{\circ}$ \\
\hline
\end{tabular}

TMA=test multidimensionale dell'autostima; Exp gr=experimental group; Co gr=control group.

parametrical analysis, through the statistic software for Social Sciences SPSS (IBM SPSS Statistics for Windows, Version 19.0. IBM Corp. Armonk, NY, USA). The data have been previously tested to verify the possible application of the parametrical tests. The KolmogorovSmirnov's test has been used to verify the normality of the distribution of the TMA scores and the BRQ $(P>0.05)$, and the Levene's test has been used to verify the homogeneity of the variances between the groups ( $\mathrm{P}>0.05$ ).

The Multivariate Analysis of Variance (MANOVA) has been calculated through continuous variables (i.e. the scores got through the TMA) in order to investigate likely differences between the experimental and control group with regard to the self-esteem levels. Then, the MANOVA has assessed the valence of the sibship in relation to the self-perception of the asthmatic children.

Furthermore, Pearson's $r$ coefficient of correlation has been calculated, for the experimental group, to verify likely statistically significant correlations between each factor of the sibship as a resource. They have been measured through the BRQ (scaffolding, decision making and emotional sharing), while the self-esteem dimensions have been measured through the TMA scales (interpersonal, per-
Table 2. The TMA (test multidimensionale dell'autostima) scores: differences between the experimental group $(\mathrm{N}=40)$ and the control group $(\mathrm{N}=30)$.

\begin{tabular}{lcc} 
Self-esteem (TMA) & $\mathrm{F}(\mathrm{df} 1.69)$ & Sign. \\
Interpersonal scale & 0.003 & 0.958 \\
Environmental mastery scale & 0.046 & 0.831 \\
\hline Emotional scale & 14.24 & $0.001^{*}$ \\
Corporealness scale & 11.76 & $0.001^{*}$ \\
\hline
\end{tabular}

R Squared $=0.000$ (Adjusted R Squared $=0.015$ ) $* \mathrm{P}<0.01$.

Table 3. The brother as a resource questionnaire (BRQ) scores: experimental group scores $(\mathrm{N}=40)$ and expected mean scores.

\begin{tabular}{lcc} 
BRQ & $\begin{array}{c}\text { Mean score of the } \\
\text { experimental group } \\
(\mathrm{N}=40)\end{array}$ & $\begin{array}{c}\text { Range of expected scores } \\
\text { on the experimental group }\end{array}$ \\
Scaffolding & 941 & Low $=480-800$ \\
& Mean $=801-1120$ \\
& High $=1121-1440$ \\
Decision making & Low $=160-266$ \\
& 335 & Mean $=267-372$ \\
& High $=373-480$ \\
\hline Emotional sharing & 380 & Low $=200-333$ \\
& & Mean $=334-467$ \\
& High $=468-600$ \\
\hline
\end{tabular}

Table 4. Correlations between indicators of self-esteem and indicators of the relationship perception with brothers (Pearson Correlation) in the experimental group $(\mathrm{N}=40)$.

\begin{tabular}{lccc} 
Indicators of self-esteem (TMA) & \multicolumn{2}{c}{$\begin{array}{c}\text { Indicators of perception of the relationship with brothers (BRQ) } \\
\text { Decision making }\end{array}$} & $\begin{array}{c}\text { Emotional sharing } \\
\text { Scaffolding }\end{array}$ \\
Interpersonal scale & 0.196 & $0.256^{*}$ & -0.067 \\
Environmental mastery scale & $0.351^{*}$ & 0.193 & -0.034 \\
\hline Emotional scale & 0.064 & 0.026 & -0.018 \\
Corporealness scale & $0.273^{*}$ & -0.004 & 0.123 \\
\hline
\end{tabular}

TMA=test multidimensionale dell'autostima; $\mathrm{BRQ}=$ brother as a resource questionnaire; ${ }^{*} \mathrm{P}<0.005$.

Table 5. Regressions for the TMA (test multidimensionale dell'autostima) corporealness scale.

\begin{tabular}{lccccccc} 
Independent variables & $r$ & $r$ square & $r$ square change & F change & Df 1 & Df 2 & Sig. F change \\
Scaffolding & 0.26 & 0.070 & .070 & 2.84 & 1 & 38 & 0.100 \\
Decision making & 0.012 & 0.000 & 0.000 & 0.005 & 1 & 38 & 0.94 \\
\hline Emotional sharing & 0.22 & 0.052 & 0.052 & 2.08 & 1 & 38 & 0.15 \\
\hline
\end{tabular}


ception of competence, emotionality and corporealness). After the correlational analysis, linear regressions have also been performed to verify the possible predictive effect of the factors of the relationship with a sibling in relation to the self-esteem.

\section{Results}

With regard to the self-esteem levels of the children involved in the study, the descriptive analysis of the results acquired from the different scales of the TMA has highlighted the presence of total levels of self-esteem (total score of TMA) classifiable as standard in both groups, even though the standard score acquired by the group of sibling-free children with asthma is lower than the standard score acquired by the children with a sibling (experimental group: 94; control group: 86). Equally, the scores of the two groups gathered from each scale of the test, i.e. in relation to the selfesteem dimensions, are within the standard levels. Only the corporealness scale reports a slightly negative score got by the control group (standard score $=80$ ) (Table 1).

The same scale of corporealness has delivered results through the MANOVA that show a statistically significant difference between the scores obtained by the experimental group and those gained by the control one $\left(\mathrm{F}_{(1-69)}=11.76\right.$, $\mathrm{P}<.001)$. A further significant difference between the two groups has emerged via the emotionality scale $\left(\mathrm{F}_{(1-69)}=14.24, \mathrm{P}<.001\right)$, where the control group has once more obtained the lower score, 86 equal to the 17 th percentile, compared with the experimental group's score, 98 equal to the 46th percentile, albeit both scores are within the standards (Table 2). With regard to the scores relating to the three factors of sibship as a resource, the data report scores that are in the mean range for each of the three scales (Table 3). Thus, the scaffolding factor has obtained the standard score $23.5, \mathrm{SD}=4.7$ within the relevant average scores from 20 to 27; the decision making factor has obtained the standard score 8.4, $\mathrm{SD}=1.3$, within the relevant average scores from 7 to 9; and the emotional sharing factor has obtained the standard score $9.5, \mathrm{SD}=1.9$, within the relevant standard scores from 9 to12. The results regarding the possible correlations between the self-esteem indicators (TMA scales) and the perception of the sibship indicators (BRQ scales) show statistically significant correlations between the self-esteem scale, as for the corporealness factor, and the scaffolding as the factor of the sibship $(r=0.273 ; \mathrm{P}<0.005)$; between the scale of the perceived competence and the scaffolding $(\mathrm{r}=0.351 ; \mathrm{P}<.005)$; and between the selfesteem scale, as for the interpersonal competences, and the decision making factor of the sibship $(\mathrm{r}=0.256 ; \mathrm{P}<0.005)$ (Table 4).

Considering such statistically significant correlations, the predictive effect of the factors of the relationship with a sibling with regard to the self-esteem has been measured through a linear regression analysis. This assessment has highlighted only one predictive effect: the scaffolding factor of the sibship in relation to the self-esteem as a competent subject $\left(\mathrm{r}^{2}=0.115 ; \mathrm{df}=38 ; \mathrm{P}=0.03\right)$ (Tables 5-8).

\section{Discussion and Conclusions}

This study has explored the connection between the self-esteem levels and the perception that children suffering from asthma have of their own interaction with an older or peer sibling. The starting point was the hypothesis that the perception of sibship, as a relational context based on the scaffolding, emotional sharing, and decision making factors, may have a predictive valence of the self-esteem levels at different dimensions. Such focus is in contrast to much of the literature of the field that has investigated specific psychological functioning variables of parents and/or healthy siblings in pediatric chronic pathology condition. ${ }^{32,33}$ It has emerged the trend to examine the likely psychological sufferance of healthy siblings, while it has hardly ever investigated the significance that the sibling interaction may have as a developmental support for both the asthmatic and healthy siblings. Therefore, the choice of shifting the point of view by considering the sibling interaction as an external resource, functional to the asthmatic child's evolutional welfare, is concurrently the innovative and strong point of this study. It is in accordance with the constructs of Pediatric Psychology, 34 that makes the research aiming at exploring the child's internal and external

Table 6. Regressions for the TMA (test multidimensionale dell'autostima) emotional scale.

\begin{tabular}{lcccccccc} 
Independent variables & $r$ & $r$ square & $r$ square change & F change & Df 1 & Df 2 & Sig. F change \\
Scaffolding & 0.046 & 0.002 & 0.002 & 0.079 & 1 & 38 & 0.78 \\
Decision making & 0.023 & 0.001 & 0.001 & 0.021 & 1 & 38 & 0.88 \\
\hline Emotional sharing & 0.101 & 0.010 & 0.010 & 0.38 & 1 & 38 & 0.53 \\
\hline
\end{tabular}

Table 7. Regressions for the TMA (test multidimensionale dell'autostima) environmental mastery scale.

\begin{tabular}{lccccccc} 
Independent variables & $r$ & $r$ square & $r$ square change & F change & Df 1 & Df 2 & Sig. F change \\
Scaffolding & 0.33 & 0.115 & 0.115 & 4.93 & 1 & 38 & 0.032 \\
Decision making & 0.22 & 0.049 & 0.049 & 1.95 & 1 & 38 & 0.17 \\
\hline Emotional sharing & 0.079 & 0.006 & 0.006 & 0.237 & 1 & 38 & 0.62 \\
\hline
\end{tabular}

Table 8. Regressions for the TMA (test multidimensionale dell'autostima) interpersonal scale.

\begin{tabular}{lccccccc} 
Independent variables & $r$ & $r$ square & $r$ square change & F change & Df 1 & Df 2 & Sig. F change \\
Scaffolding & 0.19 & 0.036 & 0.036 & 1.42 & 1 & 38 & 0.24 \\
Decision making & 0.26 & 0.067 & 0.067 & 2.74 & 1 & 38 & 0.106 \\
\hline Emotional sharing & 0.012 & 0.000 & 0.000 & 0.005 & 1 & 38 & 0.94 \\
\hline
\end{tabular}


evolutional resources that can support him/her while facing the evolutional risk posed by the disease and treatment. ${ }^{35}$

The small size of the sample is a limit. However, it is worth pointing out that the selection has been restrained by the atypical nature of the development of the subjects, and by the age variable as well.

In more detail, the results, on confirming the research hypothesis, would highlight the valence of the sibship as a protection factor that can be useful to the asthmatic children's development. Such relationship emerged to be perceived by the children with asthma involved in the study as a relational context where they can experience emotional intimacy, sense of caregiving, comparison, guide, help, and mutual cooperation in front of challenges. All this would convey not only to foster a process of strengthening of the competences of adjustment and self-esteem, which are vital to moderate the effects of anxiety and sense of lack of expertise often brought by chronic pathologies, but also to ease the coping process. ${ }^{26}$ Several research projects related to the Developmental Psychology have stressed the significant correlation between self-esteem and wellbeing, which has often ascribed to good social interactions especially with peers. Thus, a relationship with significant peers, perceived as a shared supporting source, may empower the self-esteem in typical as well as atypical development. Sibship between healthy and sick children is an evolutional resource that becomes irreplaceable in the management of the criticalities linked to disease and/or treatment (e.g. asthma attacks). The healthy child is a sort of ally who accompanies the sick sibling, at both emotional and practical level, along the natural history of the disease from the diagnosis to its treatment. Sibship, perceived as a support, points to consider that the healthy siblings of the children with asthma, involved in the research, would have tent to play an active role in their own sibling's disease experience, and that they have felt part of their world looking at the events also from this new perspective. Particularly, it would seem that this alliance interaction has a scaffolding function, and that it is predictive of the construction of a proper self-image, in terms of the positive evaluation of the corporealness, as well as of a higher sense of competence, in terms of awareness of personal skills useful to the psychosocial adjustment. A healthy sibling who plays a scaffolding role always sustains the sick sibling, and tries to find achievable solutions together. When one of the siblings suffers from a chronic pathology, sibship functions as the moderating variable of the relation between disease and its effects on development. Thus, relationship between siblings functions as a relational resource of children with asthma, through which it can be possible to depower the likely effects of disease and its treatment on the sick child's self-image. Concurrently, the selfesteem of the healthy sibling, who plays the role of an ally, may be empowered when his/her competences will be recognized.

The inferences drawn by the results of the study suggest some implications at the level of the research, as well as of the intervention. With regard to research, the valence of the relationship between siblings for the development of children with asthma, described in this study, leads towards setting up further heuristic paths following this direction, preferably with a cross-cultural perspective. Therefore, it is hypothesized the investigation of the healthy sibling not only from the point of view of his/her likely psychological sufferance, but also from the perspective of the possibility to represent an interrelated advantage in terms of evolutional resource for the sick sibling and for him/herself as well. Moreover, a further extension of this study is expected by adding a comparison between children with asthma and children suffering from another chronic disease, in order to assess the effective weight of the type of chronicity on the evolutional valence of sibship.

In relation to the effects of this study on interventions, it is worth pointing out the importance of an active involvement of siblings in the process of cure and care of children with asthma, since the diagnosis, along each crucial stage of chronicity, starting treatment, possible change of treatment, etc. It would be de facto meaningful if the staff of health and psycho-educational workers operating in outpatient departments considered the presence of an almost peer sibling as an important resource for the quality of the compliance of both child and family. That means let healthy children take the role of precious allies in the cure and care process of children with asthma. Such an involvement of healthy siblings assumes the achievement of a mutual advantage, in that the sick child is offered sustain, and the healthy one has the chance to improve his/her evolutional development.

\section{References}

1. Global Initiative for Asthma. Linee guida italiane. 2009. Available from: http://www.sunhope.it/asma\%20linee $\% 20 \mathrm{~g}$ uida\%20gina.pdf

2. Bachert C, van Cauwenberge P. The WHO ARIA (Allergic Rhinitis and Its Impact on Asthma) Initiative. In: Markert UR, Elsner P, eds. Local immunotherapy in allergy. Basel: Karger; 2003. pp 119-126.

3. Asher M, Montefort S, Bjorksten B, et al. Worldwide time trends in the prevalence of symptoms of asthma, allergic rhinoconjunctivitis, and eczema in childhood: ISAAC phases one the three repeat multicountry cross-sectional survey. Lancet 2006;368:733-43.

4. Liu AH, Covar RA, Spahn JD, et al. Asma infantile. In: Marcdante KJ, Kliegman RM, Jenson HB, Behrman RE, Nelson, eds. Manuale di Pediatria. San Diego, USA: Elsevier Inc; 2012.

5. Perricone G, Polizzi C, Morales MR, et al. La rappresentazione del sé corporeo in bambini con patologie croniche diversamente trattate. SIPSA 2011;1:51-65.

6. Thomas M, Burton A, Moffat M, et al. Asthma and psychological dysfunction. Prim Care Respir J 2011;20:250-6.

7. Tibosch MM, Verhaak CM, Merkus PJFM. Psychological characteristics associated with the onset and course of asthma in children and adolescents: a systematic review of longitudinal effects. Patient Educ Couns 2011;82:11-9.

8. Vila G, Nollet-Clemençon C, De Blic J, et al. Prevalence of DSM IV anxiety and affective disorders in a pediatric population of asthmatic children and adolescents. J Affect Disord 2000;58:223-31.

9. Walker BJ, Stokes LD, Warren R. Environmental factors associated with asthma. J Natl Med Assoc 2003;95:152-66.

10. American Academy of Allergy Asthma and Immunology. Pediatric asthma: promoting best practice guide for managing asthma. Milwaukee, WI: American Academy of Allergy Asthma and Immunology; 2002.

11. Careddu P, Castelli MA, Giuffre' L, et al, eds. Pediatria generale e specialistica. Milano: Casa Editrice Ambrosiana; 2002.

12. Bouchard TJ Jr, Loelhin JC. Genes, evolution, and personality. Behav Genet 2001;31:243-73.

13. Rutter M. Genes and behavior. Nature-nurture interplay explained. Oxford: Blackwell Publishing; 2006.

14. Baldini L. Psicologia Pediatrica . Padova: Piccin; 2009.

15. Soliday E, Kool E, Lande MB. Family environment, child behavior, and medical indicators in children with kidney disease. Child Psychiatry Hum Dev 2001;31:279-94.

16. Adams RJ, Wilson DH, Taylor AW, et al. Psychological distress and quality of life among people with asthma in the Australian population. Respirology 2003;8:67-81.

17. Perricone G, Morales MR, Polizzi C, et al. Schemi narrativi sul sé e autostima nel bambino con neoplasia: uno studio pilota pre-test. Minerva Pediatrica 2010;62:4350.

18. Rotter JB. Generalized expectancies for internal versus external control of reinforcement. Psychol Monogr 1966;80:1-28. 
19. Winter MA, Fiese BH, Spagnola M, Anbar RD. Asthma severity, child security, and child internalizing: using story stem techniques to assess the meaning give to family and disease-specific events. J Fam Psychol 2011;25:857-67.

20. Penza-Clyve SM. Patterns of emotion regulation coping in children with asthma and diabetes. In Dissertation Abstracts International: Section B: The Sciences \& Engineering. Ann Arbor: University Microfilms; 2000. pp 5786.

21. Miller BD, Wood BL. Influence of specific emotional states on autonomic reactivity and pulmonary function in asthmatic children. J Am Acad Child Adolesc Psychiatry 1998;36:669-77.

22. McQuaid EL, Kopel SJ, Nassau JH. Behavioral adjustment in children with asthma: a meta-analysis. J Dev Behav Pediatr 2001;22:430-9.

23. Zielinski TA, Brown ES. Depression in patients with asthma. Adv Psychosom Med 2003;24:42-50.

24. Gandhi PK, Kenzik KM, Thompson LA, et al. Exploring factors influencing asthma control and asthma-specific health-related quality of life among children. Respir Res 2013;14:26.

25 Barlow JH, Ellard DR. The psychosocial well-being of children with chronic disease, their parents and siblings: an overview of the research evidence base. Child Care Health Dev 2006;32:19-31.

26. Dahlbeck DT, Lightsey OR Jr. Generalized self-efficacy, coping, and self-esteem as predictors of psychological adjustment among children with disabilities or chronic illnesses. Child Health Care 2008;37:293-315.

27. Repetti RL, Taylor SE, Seeman TE. Risky families: family social environments and the mental and physical health of offspring. Psychol Bull 2002;128:330-66.

28. Kaugars AS, Klinnert MD, Bender BG. Family influences on pediatric asthma. J Pediatr Psychol 2004;29:475-91.

29. Stentella C. Essere fratelli di ragazzi con disturbi psichici. In: Piperno R. Segnali da un mondo sommerso. Essere fratelli di ragazzi con problemi. Roma: CCSC; 2006.

30. Perricone G, Fontana V, Burgio S, Polizzi
C. Sibling relationship as a resource for coping with traumatic events. Springerplus 2014;3:525.

31. Bracken BA. Test TMA, valutazione multidimensionale dell'autostima. Trento: Erickson; 1993.

32. Murray JS. Social support for school-aged sibling of children with cancer: a comparison between parent and sibling perceptions. J Pediatr Oncol Nurs 2001;18:90104.

33. Sharpe D, Rossiter L. Siblings of children with a chronic illness: a meta-analysis. J Pediatr Psychol 2002;27:699-710.

34. La Greca AM, Schuman W. Research methods in pediatric psychology. In: Kendall PC, Butcher JN, Holmbeck GN eds. Handbook of research methods in clinical psychology. New York: John Wiley \& Sons; 1999.

35. La Greca AM, Mackey ER. Adherence to pediatric treatment regimens. In: Roberts MC, Steele RG eds. Handbook of pediatric psychology. New York: The Guilford Press; 2009. 